\title{
A Case Study of Engineering Faculty Collaboration: Co-Authoring an E- Book on Energy and Sustainability
}

\section{Dr. Bugrahan Yalvac, Texas A\&M University}

Bugrahan Yalvac is an associate professor of science education in the Department of Teaching, Learning, and Culture at Texas A\&M University, College Station. He received his Ph.D. in science education at the Pennsylvania State University in 2005. Prior to his current position, he worked as a learning scientist for the VaNTH Engineering Research Center at Northwestern University for three years. Yalvac's research is in STEM education, 21st century skills, and design and evaluation of learning environments informed by the How People Learn framework.

\section{Dr. Mehmet Ayar, TUBITAK}

Dr. Mehmet Ayar is a scientific programs expert in the Scientific and Technological Research Council of Turkey (TUBITAK). He received his PhD. in Curriculum and Instruction with specialization in STEM education at Texas A\&M University in 2012. His research is in ethnographic studies of science and engineering practice, curriculum development, design of learning environments and robotics activities. Dr. Ayar worked for the Live Energy Project during his PhD studies at Texas A\&M University. Prior to his PhD studies, he worked for three years as a science teacher at a private school in Turkey.

\section{Dr. Dennie L. Smith, Texas A\&M University}

Dennie Smith is a Professor in Teaching, Learning and Culture at Texas A\&M University.

\section{Dr. Christine Ehlig-Economides, Texas A\&M University}

Dr. Ehlig-Economides has been full professor of petroleum engineering at Texas A\&M University in the Albert B. Stevens endowed chair since 2004. Before that she worked for Schlumberger for 20 years in well test design and interpretation, integrated reservoir characterization, modern well construction design, and well stimulation. She has worked in more than 30 countries and authored more than 60 papers. Dr. Ehlig-Economides has received a number of technical awards in including the SPE Formation Evaluation and Lester C. Uren Awards and the Anthony Lucas Gold Medal, and she was inducted into the National Academy of Engineering in 2003. 


\title{
A Case Study of Engineering Faculty Collaboration: Co- Authoring an E-Book on Energy and Sustainability
}

\begin{abstract}
In this paper, we discuss the characteristics of the interaction and the culture that emerged as five engineering professors across the US engaged in a unique pedagogical activity to promote more student-centered instruction. In this three-year collaborative project funded by the NSF, the professors co-authored an electronic textbook in energy sustainability in order to optimize student learning with up-to-date and relevant content. Four learning scientists and a team of technology experts also consulted with the professors. Framed by a case study design and utilizing ethnographic data collection approaches, the authors explored and documented the community of practice characteristics of the professors' interactions. Study data included the recordings of the weekly meetings over two years and one-to-one interviews with the professors. We report and discuss the professors' emergent individual identities, their common language and repertoire, evolution of their mutual engagement and development of community goals, and the discourse of their interactions where they both practiced their common tasks and learned from each other.
\end{abstract}

\section{Study Purpose}

The purpose of this study was to explore the community-of-practice characteristics of five engineering professors' interactions in authoring a dynamic and electronic textbook on energy and its sustainability topics.

\section{Study Rationale}

Developing dynamic and electronic textbook material to teach college courses represents an innovative pedagogy in higher education. Because of newly emerged energy sustainability content knowledge, changes in environmental factors, and media and public reactions to those changes, there appears a need to use a textbook with dynamic content that can be updated periodically. Our faculty members and the National Science Foundation (NSF) have realized the need for dynamic content material in teaching energy and sustainability topics. The project was initiated in September 2010. The overarching goal of the project was to enhance college students' learning experiences by showing the relevance of the content knowledge they learn in class and hear about through mass media and elsewhere, and by communicating the transdisciplinary nature of energy sustainability. Socio-scientific issues ${ }^{1}$ and recent environmental and political events were deemed central to the content of the book. Among the other goals of coauthoring a dynamic-and-electronic textbook were to cultivate $21^{\text {st }}$ century skills, including lifelong learning and critical thinking abilities.

Co-authoring dynamic textbook material is not a typical educational activity. It is unknown how the authors' interactions and communication will evolve over time and what characteristics of the culture will develop as they work in collaboration. Utilizing the communities-of-practice framework $^{2,3}$, one can identify the faculty's co-authoring collaboration as an opportunity to explore their emerged culture and learn from their discourse and community characteristics. The 
findings can inform other educational efforts and provide an exemplary framework for similar studies where learning is perceived as participating in a community-of-practice.

\section{Theoretical framework}

Energy and its sustainability are essential for modern societies to survive and sustain their socioeconomic and environmental characteristics. For sustainable energy consumption and management, three key factors need to be considered: environment, society, and economy. For informed decisions on energy sustainability issues, expertise from not only engineering and technical fields but also expertise is needed from other disciplines including economics and other social sciences.

Many universities have recognized the trans-disciplinary nature of teaching and learning about energy sustainability and have begun offering energy sustainability courses to students in all majors $^{4,5}$. Not very different from other newly emerged fields (e.g., biomedical engineering, nanotechnology, etc.), energy and sustainability topics do not have a prescribed and longexisting content knowledge base. An up-to-date textbook for teaching the trans-disciplinary characteristics of energy and sustainability topics and their interrelations with society, environment, and economy is not readily available in a printed format. Thus, this project was timely.

The notion of community of practice has been discussed in the education literature ${ }^{2,6,7}$. In his essay titled "Communities of Practice," Wenger proposed that people learn in practice ${ }^{2}$. That is, learning naturally occurs when people form a community of practice and perform a task that is meaningful for all participating members. This orientation towards the theory of learning is aligned with the student-centered pedagogies described in How People Learn by Bransford, Brown, \& Cocking ${ }^{8}$. It also has connotations with social learning theories, that is, social interaction and communication are sine quo non for humans to learn'.

Wenger $^{2}$ identified a community-of-practice involving three characteristics: (a) mutual engagement, (b) joint enterprise, and (c) shared repertoire. Mutual engagement refers to a membership in a community where members establish norms as well as individual identities and build social relationships that keep the members of the community together. Joint enterprise, which is not a fixed or static entity, is a result of a collective process of negotiation among the group members. A predefined goal or a project objective is not a joint enterprise. A joint enterprise emerges over time because of the collective activities. Wenger defines a shared repertoire as a set of resources a community produces through interaction and negotiation. In a community-of-practice, the mutual goals evolve over the course of the community activities and within the discourse of the community interaction, personal identities emerge. Experts in the community often have different identities from the newcomers' who have recently joined the community. Learning occurs as newcomers participate in the project activities and begin to develop their own identities within the discourse of the interaction.

It is likely that in the near future most undergraduate course textbooks will be dynamic in content and co-authored by many individuals at the same time. This is particularly the case for the textbooks in trans-disciplinary courses. Currently, e-copies of many textbooks are available. 
Students can access them on the Internet or read the downloaded copies on their electronic gadgets (e.g., Kindle, Ipad, smart phone and other tablets). The learner-centered pedagogies require the knowledge students learn to be the most relevant to their daily life experiences. For the students to find meaningful connections between the textbook knowledge they read and their daily life experiences, the knowledge represented in the books should be the most recent. This requires the textbook authors to update their textbook as often as possible. How the authors work in collaboration and what characteristics of the culture emerge through this interaction are unknown. Exploring this culture and documenting its characteristics will inform learning scientists in their efforts to lead future co-authors and engage them in similar student-centered instruction.

\section{Methods}

In this study, we used the communities-of-practice concept ${ }^{2}$ to analyze faculty collaboration and the culture that emerged. The present study was an instrumental, single-case study design ${ }^{10}$. The case under investigation was faculty collaboration. An ethnographic data collection and analyses approach was used to describe practices and conditions that contributed to the development of a culture of collaboration for producing dynamic instructional content for teaching about energy and its sustainability ${ }^{11,12,13}$. Data included the recordings of weekly meetings, one-to-one interviews with the faculty ${ }^{14}$, and the documentation of all electronic interaction.

\section{Data Sources}

The primary source of the ethnographic data was the actual conversations of the engineering professors as they co-authored the textbook. Because the participating professors were located across the US (two members were on the East Coast, one in the South, and two on the West Coast), the majority of their verbal communication occurred in the weekly teleconference meetings through the Adobe Connect software. These meetings were recorded, transcribed, and served as the primary data source for the study.

A secondary source of data was the individual interviews with the engineering professors. A learning scientist who did not participate in the meetings conducted the one-to-one meetings. Interviews lasted around 45 minutes, were recorded, transcribed, and examined for common themes that characterized the professors' experiences and opinions. In addition, the electronic documentations of the work professors generated were examined. Professors organized and communicated their electronic media through the "Google Documents" and "drop box" tools.

This study was approved by the Institutional Review Board at the main campus of the project. The professors' signed consent approvals were collected before conducting the interviews and their rights as participants in the study were explained. All five professors volunteered for participation in the study. Names of the participants were changed in the following discussion in order to protect their confidentiality. 


\section{Participants}

Our study participants are five engineering professors who served as principal investigators of the project in five campus locations. These five professors also interacted with the learning scientists and the technology experts at the weekly meetings and in completing the project activities. The founder of the project is one of the engineering professors in the leading campus. Prior to the present project's activities, the lead engineering professor completed a TUES (Transforming Undergraduate Education in Science, Technology, Engineering, and Mathematics program) Type I project to develop a student-centered undergraduate energy course. She has a history in working with the leading learning scientists and the technology expert of the present project since 2007. The present project is a TUES Type II, that is an extension of the first project. The leading engineering professor had contacted the other engineering professors in four different locations across US. One campus that is in the same state with the leading campus was primarily chosen because it historically represents a minority serving institution. The two other campuses host well-respected programs in petroleum engineering and in earth and mineral sciences. In the fourth campus location, the professor has considerable experience in authoring textbooks in energy sustainability and he is the author of the mostly used textbook in the field. The leading professors invited the other four professors to work together for the present project and they launched the project activities in 2010. The learning scientists in the leading campus have met with the other engineering professors online and face-to-face only a few times during the conference attendances. Table 1 summarizes the characteristics of the five engineering professors.

Table 1. The five engineering professors' (the primary study participants') characteristics and their teaching context

\begin{tabular}{llllll}
\hline Participant & $\begin{array}{l}\text { Campus } \\
\text { location }\end{array}$ & Sex & $\begin{array}{l}\text { Years of } \\
\text { teaching in } \\
\text { academia }\end{array}$ & $\begin{array}{l}\text { Number of } \\
\text { courses taught } \\
\text { per semester }\end{array}$ & $\begin{array}{l}\text { Approximate number of } \\
\text { students enrolled in the } \\
\text { energy course per } \\
\text { semester or quarter }\end{array}$ \\
\hline Professor 1 & South US & Female & $>10$ & $1-2$ & $80-120$ \\
Professor 2 & South US & Male & $>5$ & $1-2$ & $10-20$ \\
Professor 3 & East Cost & Male & $>5$ & $1-2$ & $100-300$ \\
Professor 4 & West Cost & Male & $>25$ & $2-3$ & $100-300$ \\
Professor 5 & West Cost & Male & $>15$ & 2 & $50-125$ \\
\hline
\end{tabular}

\section{Analyses}

The majority of the recorded weekly meetings and all interview conversations were transcribed verbatim. In our analysis of the transcriptions, we employed the constant comparative method ${ }^{14}$. We read the transcriptions several times and employed open and axial coding followed by selective coding. The incidents professors described in the interviews and the themes that emerged in the weekly conversations were coded and categorized ${ }^{11,12}$. In developing the codes, we used the communities of practice notion ${ }^{2,15}$.

This is a self-study and we have been the active participants in the study context. As in any qualitative study, the findings we report here are our interpretations of the data we collected. If 
an outsider and non-participant researcher would interpret the same data, she might report different findings. Hence, we do not necessarily claim that our analysis are exclusively objective and/or our findings are free of bias.

\section{Findings}

We organized our findings along five dimensions: (a) an overview of the culture that emerged; (b) shared language; (c) individual identities; (d) mutual engagement and evolved goals; and (e) lessons learned.

\section{An Overview of the Emerged Culture}

Culture is a dynamic process and evolves as its members participate in mutual activities ${ }^{18}$. Thus, in this study, we conceived culture as a way of individuals doing things, sharing goals, practices, and values, and using their knowledge and experience in their everyday life $\mathrm{e}^{13,16,17}$.

In the culture of the five engineering professors, the pre-defined goal was to co-author an online textbook on energy sustainability to support core science and engineering courses for major and non-major undergraduate students. However, the joint enterprise evolved over time. Professors decided to publish the book on an e-book reader (e.g., Kindle or iPad) that would be more convenient to read. Most recently, iBook Author was used to publish the book. A team of technology experts designed the iBook and the professors provided the content. Another goal that emerged was to sustain the book after the project funding ended. In a virtual faculty meeting, Melissa articulated their goal as follows:

...We want to create a book that will generate enough revenue because students pay for it that we can sustain capability of the regular updating, things to keep up with...that's very dynamic energy environment. So it is not just course material.

In his interview, Samuel said:

... Originally, we thought it is going to be...web-based material, we did not think about an e-book...for sustaining this book or revenue to keep up with information. Original one was to create some web-based material that can be used by everybody, and adopt this one from not only our five schools, but other schools also.

The virtual culture of the professors included normative interactions among the members. They met once in every week for at least one hour using the Abode Connect program. Adobe Connect provided a means for each member to sustain their participation in the community and engagement with each other from different locations across the country with different time zones. In other words, Adobe Connect was the communication platform that allowed them to come together and to coordinate their participation and communication in the virtual collegial.

In addition to the five engineering professors, the learning scientists, and the technology experts, other people joined the group activities and the weekly meetings. Thus, this culture was enlarged as newcomers (e.g., two new learning scientists and two new engineering professors) joined the 
weekly meetings. Each individual, regardless of their expertise, experience, and education level, was welcomed to share knowledge and experience to accomplish the groups' joint enterprise.

During the course of the conversations, we observed that one professor, Melissa, led the weekly meetings. She set the agenda and orchestrated discussions and negotiations among the members. She did not oppress other participants' actions; but rather welcomed everyone to share ideas, bring up any issues, and make comments about the topics discussed during the meetings. More importantly, the group made their decisions in a collaborative manner.

Faculty members described their interactions as not unlike other academic meetings. Each member was open to criticism and welcomed others' opinions. In his interview, Thomas said:

...It is the usual kind of interaction that we have...it is not any different, let's just say, than any other kind of interaction...I have worked on several... organizing several sort of industry meetings for the society of Petroleum Engineers...the interactions again are very similar to that sort of interaction.

Richard said:

My interaction was limited because I was someone who has trouble... with the computer...you know...technical stuff...that has not always worked...now it seems like we are doing it okay...but our meetings are very useful...we learn about others' point of view...bring some issues to talk and discuss.

During their meetings, the engineering professors discussed assigning the chapter authors, administration of the pre and post research instruments, and the electronic medium in which the book would be published. They shared comments about formatting the e-book chapters, e-book publishing, and Google Docs. Not all of them were familiar with e-book publishing although they had books published in the printed format. One of the professors' experiences with e-book publishing was helpful for the group in proceeding with the project. In his interview, Richard added:

...In my experience ...the publishing companies...sometimes might have some input, while other faculty did not have exactly the same experience when they were trying...to publish more traditional books...I had some explanation to for this...they tried either to talk to some publishers and the orders of the textbooks...the chapters and things like that... basically at different doors...so in that sense I had delivered more experience than some others had.

The professors could easily write the assigned chapters within their content expertise but e-book publishing presented unfamiliar technical, economic, and social dimensions. They became aware of these dimensions as they continued to communicate and discuss e-book publishing issues. The professors with traditional publishing experience and the technology expert's input helped them recognize some of the issues. Samuel said: 
...We have an IT [Information technology] person providing technical stuff using technologies and multimedia to establish the online textbook...I try to share my experience...I have given the name of a few publishers and a few e-books and some technologies.

Richard told us:

...We reviewed various possibilities.... How other people did the electronically or ebook...I shared my experiences about how I created one book online and similarly...others shared their experiences if they had any...

The technical issues were about formatting, text availability, content, figure, and formula illustrations. The professors agreed that coherence and consistency should be the criteria. The technical aspects of the e-book publishing were negotiated with the faculty members and the technology expert. Possible ideas, suggestions, and comments were shared with the technology expert in order to proceed.

One concern that was not considered before the project was initiated was the need to address the copyright issues of the images used in the book. Professors discussed the means to secure the copyrights of the images in their weekly meetings. They created a file on Google Docs and organized the permission letters and emails to send to the producers of the images. The professor participants took their own images as appropriate and worked in collaboration to receive approval for other images used in the book.

Another social context that emerged was the faculty members' peer review process. Peer review process, which was naturally occurred in the virtual collegial, was set to be established in two ways: (a) internally and (b) externally. The external peer review process is still undergoing as our professors coauthor the chapters. The internal peer review has been completed. Our professors reviewed each other's chapter for the consistency of the presentation style and the coherence of the language in the book.

\section{Shared Language}

As a group, the professors became accustomed to using several technological tools and methods in the community. These common tools and methods helped to develop a shared repertoire and a common language. Among these tools and methods were the content questionnaire organization and administration techniques, the unique communication technique in Adobe Connect, and engineering problem solving techniques. For instance, in the content questionnaire administration technique, the professors worked with a graduate student on the main campus yet shared their experiences in the meetings with others. The student designed the content questionnaire on Remark software. The Scantron forms were emailed to each faculty member. Each professor then printed out the emailed form and followed other specific guidelines that were provided. It was required for each school to print out a "master" form and not use this one but make copies out of that one, so that all copies would have the exact alignment with the "master" copy. When we collected the completed surveys back, we used the "master" copy as the answer key and according to the "master" copy's alignment, Remark software was able to 
score all the other forms students had completed in a particular institution. Because each school had a different printer and each master copy was printed out from a different printer, we used the same procedure for all schools. This technique has emerged within our community and is an example of the tools and techniques we utilized to perform our community tasks. The knowledge for this technique has been learned naturally by all members as they performed their practices within the community. We did not need to instruct the professors and/or teach them how to complete this process

As the professors communicated with each other on Adobe Connect, they discussed the book chapters and the table of contents. Each professor had expertise in different areas of energy. A commonality that we observed among the professors was their approaches to problem solving. It is likely that because of their engineering field, our professors practiced engineering problem solving techniques whenever they had an issue to resolve during their communication with each other. First the problem was clearly identified and then everyone in the group contributed their input to solve the problem. Among the multiple solutions provided, the group collaboratively decided on the best working solution. In his interview, Thomas said:

...You could talk about...you could organize [energy topics] different ways...I mean we developed some sense of language around that...instead of just talking about this is oil, this is natural gas, this is nuclear, this is renewables, in terms of energy we did not talk just about the forms of energy, but we have a little bit of historical content and then what is energy and what is sustainability and then for every sort of class of energy...how the energy resource...is used... it is a common organization of the way to view to topics of energy...I think we sort of brought in the engineering problem solving approach, which is you sort of identify the problem, you debate various solutions... you choose a way forward and sometimes...choosing the best parts of various ideas that people put forward and sort of mixing them together and making something out of it that has pieces of everybody's thoughts.

\section{Individual Identities}

Each professor developed an individual identity. For example, in the submission and the administration of the IRB forms, professors completed this task in different ways. One professor believed that her students should not be limited by time when they completed the content questionnaire and did not need to be observed as they answered the content questionnaire items. Therefore, she gave the content questions to her students, and the students were free to fill them in at their home, at their own pace, and were trusted not to cheat or search for the answers from another source, e.g. the Internet. This faculty's identity in the project was different from the others as to how she treated her students and relied on their honesty. Other professors assumed that students might check the Internet or other resources as they answered the content questionnaire items, or inform students of the questions before they did the survey and preferred administering the content questionnaire in class.

As the professors administered the engineering attitude, critical thinking, and life-long learning surveys to their students, one utilized her institution's software explaining that it would be more secure than using Survey Monkey. She was more of a technology user than the other faculty in 
the group. As another example, one faculty member administered both the content questionnaire and the surveys to two classes in her institution, one of which she did not teach. She wanted to populate the number of students completing the study instruments in her institution to help increase the reliability and the validity of the study's instrumentation.

We welcomed the administrative differences among the professors in different campuses. Our learning scientists did not restrict the professors' teaching style or their questionnaire administration techniques. Other than the IRB requirements, we let the professors practice their own style in their classrooms. Fortunately, we have planned collecting both control and experimental student data from each participating institution that will allow us to identify the campus differences (using the institutions as co-variance) and control if marginal differences are observed.

\section{Mutual Engagement and Evolved Goals}

Each professor sustained participation in this study through weekly meetings in the virtual environment. In these meetings ideas, strategies, and goals were shared with each other. Each participant internalized that the primary project purpose was to co-author an online textbook, and they developed mutual goals to accomplish this task. All professors were experts in different energy related topics and brought their unique backgrounds and experiences to the project. In order to develop a coherent product, however, the group had to define and specify target users, or audience. Thus, an early goal emerged in the project to identify how different types of energy sources ought to be presented to the target audience. In his interview, Thomas stated:

...Decide what educational level you are basing that this is going to be written for. So is this something for the expert user or is this something for...for like a freshman. So in this case, we went for the more introductory type of information.

Building a coherency among the chapters was another goal that emerged over the course of the project activities. In his interview, Thomas added:

...Y You need to make a coherent sort of flow of ideas as well as define, so this is about writing a book, defining who the audience is going to be, what level of technical details should there be.... again these were largely based on the whole series of conversations about where the needs were perceived to be... how is each chapter going to be presented...is there going to be some coherence from chapter to chapter...define in some way how every chapter should be organized.

Development of a common vision of the finished product ultimately emerged as an evolved goal while the professors continued to communicate with each other. It was critically important to have such an understanding to avoid being political in coauthoring an e-book about energy sustainability. In his interview, Richard added:

...you can not avoid to become partly political, you try to be totally unbiased, but we have works in different industries. Some people have worked in the oil industry so they are more in favor of that kind of thing. Some people work in the nuclear so to become 
more in the nuclear and so but when you want to write a book about energy, we have to put all of our criticism aside and we just try to have a cohesive understanding of what energy issues are...

\section{Lessons Learned}

The engineering professors learned from each other about the strategies one can use in Institutional Review Board (IRB) process, content and survey administration, and communicating the student data with the lead organization in the project. Each institution in the project had its own regulations for researchers. Each professor had to receive IRB approval to administer surveys, collect data, and send them to the lead institution where the data would be analyzed. Therefore, each professor got involved in the IRB approval process, and made and adapted modifications to their own institution the way they wanted. In his interview, Richard stated:

...using and sending out the data to another institution for analysis was a difficult thing at our institution... because of the safety of [data]...but it was... something we have to go through...we talked about these things...collectively and we just adapted to our institutions as our folks ask for information.

After the initial data collection, the team members realized that some of the content questionnaire items needed modifications. The team members reviewed the items one by one and made the necessary modifications. However, this modified version required new approval from the IRB and the professors in each institution went through another IRB approval process. The second time the professors completed the process took relatively less time.

As the professors accomplished the community activities, they learned how to appropriately use the Adobe Connect and talk in the meetings. The Adobe Connect was a means for each professor to sustain his or her participation in the weekly meetings. Yet, more often they faced technical problems (e.g., connection, hearing, echo) before their meetings began. When they had echo or could not connect to the Adobe Connect, they preferred texting in order to participate in the meetings. Both our technology expert and another professor sometimes provided the necessary instructions to deal with the technical problems. Eventually VoIP technology was abandoned in favor of conventional teleconferencing for audio communication, and this avoided most of the echo problems. Mutual interactions among the members enabled them to appropriately use the Adobe Connect as well as to maintain participation.

The dynamic characteristics of the content of the e-book were addressed several times in the meetings. The professors concluded that this characteristic was the most crucial part of the project. In a meeting, Melissa stated:

...the online book does not have to be fixed content, but it does. We have favorite content that we expect to use, so there is a sort of filter. One of the advantages of online books is that when things happen, like Fukushima and then the nuclear chapter will address this. In the oil industry, the huge blow out from BP happened last April. Things like that 
happened can be included in the e-book as long as they are critical to the subject-matter to be covered. They can come into existing chapter as often as we are ready to update.

At this point, Richard added:

I have been trying to do that [updating at least once a year]...there have been several things that happened for example, Fukushima. I definitely updated the chapter on nuclear energy. I looked at the basically how much radiation they get, what the effect is, how massive the explosion is. And a couple days ago, there was an issue between Germany and Switzerland about nuclear energy. I have been adding these recent events in the book.

\section{Discussion and Conclusions}

This study focused on the nature of five engineering professors' collaboration to write and produce an e-book. We sought to answer the extent to which the culture of the five engineering professors coauthoring an e-book on energy and its sustainability topics could be characterized as a community of practice. We concluded that the professors ultimately developed a joint enterprise as they continued to participate in weekly meetings. The virtual collegial participation in the weekly meetings became the cultural norm that each professor and other participants became accustomed to and that bound them together as a productive team. These meetings were recorded so that anyone who missed the meeting could go over the audio file to review the topics discussed and more importantly, maintain his or her membership in the team.

The norms of the professors' participation in the weekly meetings were not different from the norms of other academic meetings. Professors provided feedback to each other's ideas and respected other's opinions. In turn, they were encouraged to contribute and discuss the technical, social, and epistemic aspects of the e-book. Even though each professor was the expert in the energy-related field, they had different opinions to shape and format the e-book. Through their mutual interaction, these perspectives were brought to the fore and shared among them in order to accomplish their joint enterprise over time.

As they continued to write a draft for the e-book, the professors had difficulties with the technical and social dimensions of coauthoring practice. We conceive of these difficulties as the resistance on their way to reach their goal. Their mutual interaction through the Adobe Connect was a way to resolve these difficulties because different ideas, comments, and experience were shared and negotiated to do so. In addition, the professors had problems or concerns in regard to administering and collecting questionnaires because each institution had different technologies and techniques. Ultimately, a technique for administration and collection of the questionnaire emerged from the community naturally as they shared and negotiated their ideas and experience.

We learned that the faculty brought their engineering problem solving expertise into the project activities. The content of the e-book included chapters devoted to a variety of energy-related topics (e.g., coal, hydro, solar, wind, and nuclear) and sustainability. Thus, an early and primary concern for the professors was consistency of treatment of the topics within the chapters they were expected to write. Their solution was to apply a common scientific problem solving process to the task. They first identified the problem, which was attributed to the content of each chapter 
and technical aspects (template, formatting, figures or formulas). The second step was to discuss possible solutions (e.g., preparing a template that every faculty would use to write their chapter), and finally, to choose the best among the possible solutions in order to proceed.

The professors' individual identities developed over the course of the project and was most observable in obtaining of IRB forms and administration of the surveys to students in five different institutions by professors with different frames of reference regarding their individual institutions, their own students, and their experience backgrounds as researchers. We interpreted that one of the professors' individual identity influenced her pedagogical practice. She treated her students as reliable and honest when they were asked to complete the questionnaires and did not want to administer the questionnaires in class and thus limit the time to complete them. Another professor's individual identity was associated with her experience as a scientific researcher. From her perspective safety of data coming from the students was a credential to perform scientific research. She viewed such safety as essential to establishing reliability and validity of the data collection instruments and ensuring credibility of the study.

This study was innovative for two reasons. First, the pedagogical activity the five faculty members were engaged in was not typical practice. Second, we primarily relied upon the community-of-practice notion as the conceptual framework for the project and its study. Even though the community-of-practice notion is well known in literature, studying curriculum developers' collaboration (in this case the engineering faculty teaching their college level courses) and their emerged discourse and shared culture was a novel research practice. Documenting the cultural norms and the discourse among professionals that emerged in this project will guide other studies in the use of similar approaches and may inform other fields in the development of similar dynamic content.

\section{Acknowledgement}

This material is supported by the National Science Foundation under TUES Phase-II Grant number 1022932. Any opinions, findings, conclusions, or recommendation presented are those of the authors and do not necessarily reflect the views of the National Science Foundation.

\section{References}

[1] Sadler, T. D. (2009). Situated learning in science education: Socio-scientific issues as contexts for practice. Studies in Science Education, 45(1), 1-42.

[2] Wenger, E. (1998). Communities of practice: learning, meaning, and identity, Cambridge, MA: Cambridge University Press.

[3] Wenger, E., White, N., Smith, J., \& Rowe, K. (2005). Technology for communities. Retrieved from http://technologyforcommunities.com/

[4] Yalvac, B., Ehlig-Economides, C., Brooks, L. A., \& Smith, D., (2009, July). An international, interdisciplinary, and dynamic approach to teaching energy utilization and sustainability. Proceedings of the International Symposium on Engineering Education and Educational Technologies (EEET). Orlando, FL. 
[5] Yalvac, B., Brooks, L. A., \& Ehlig-Economides, C., (2008, June). Research on the evolution of college instructors' perspectives of teaching and learning. Proceedings of the American Society for Engineering Education (ASEE) Annual Conference and Exposition. Pittsburgh, PA.

[6] Barab, S. A., Barnett, M. G., \& Squire, K. (2002). Developing an empirical account of a community of practice: Characterizing the essential tensions. Journal of the Learning Sciences, 11, 489-542.

[7] Choi, M. (2006). Communities of Practice: An alternative learning model for knowledge creation. British Journal of Educational Technology, 37(1), 143-146.

[8] Bransford, J., Brown, A. L., \& Cocking, R. R. (2000). How people learn: brain, mind, experience, and school (2nd ed.). Washington DC: National Academy Press.

[9] Ziman, J. M. (1983). The Bernal lecture: The collectivization of science. Proceedings of the Royal Society of London, series B, biological sciences, 219 (1214), 1-19.

[10]Stake, R. E. (2005). Qualitative case studies. In Denzin N. K., \& Lincoln, Y.S. (Eds.) The sage handbook of qualitative research (3rd ed., pp. 443-466). Thousand Oaks, CA: Sage Publication.

[11]Creswell, J. W. (2012). Qualitative inquiry and research design: Choosing among five approaches (3rd ed.). Thousand Oaks, CA: Sage Publication.

[12]Denzin N. K., \& Lincoln, Y.S. (2005). The sage handbook of qualitative research (3rd ed.). Thousand Oaks, CA: Sage Publication.

[13]Geertz, C. (1973). The interpretation of cultures. NY: Basic Books.

[14]Glaser, B. G., \&Strauss, A. L. (1967). Discovery of grounded theory: Strategies for qualitative research. Chicago, IL: Aldine Publishing Company.

[15]Lave, J., \& Wenger, E. (1991). Situated learning: legitimate peripheral participation. Cambridge, MA: Cambridge University Press.

[16]Kluckhohn, C. (1949). Mirror for Man. New York: McGraw-Hill.

[17]Spradley, J.P. (1980). Participant observation. New York: Holt, Rinehart, \& Winston.

[18]Buxton, C.A. (2001). Modeling science teaching on science practice? Painting a more accurate picture through an ethnographic lab study. Journal of Research in Science Teaching, 38, 387-407. 